\title{
МЕДИКО-СОЦИАЛЬНАЯ РАБОТА С МОЛОДЫМИ СЕМЬЯМИ ПО ПРОБЛЕМЕ ПЛАНИРОВАНИЯ СЕМЬИ
}

\author{
С. П. Буриев \\ Московский гуманитарный университет, \\ А. В. Жуков \\ Благотворительный фонд «Право на чудо», г. Москва
}

Аннотация: В работе обсуждаются технологии медико-социальной работы с современными российскими молодыми семьями по вопросам планирования ребенка, предупреждения и коррекции возможных расстройств здоровья у новорожденных, в частности, по проблеме выхаживания недоношенных детей.

Ключевые слова: технологии социальной работы; молодая семья; новорожденный; здоровье; планирование семьи; благотворительность

\section{MEDICAL AND SOCIAL WORK WITH YOUNG FAMILIES ON FAMILY PLANNING}

\author{
S. P. Burtsev \\ Moscow University for the Humanities \\ A. V. Zhukov \\ Charity Fund «Right to a Miracle»
}

Аннотация: The paper discusses the technologies of medical and social work with modern Russian young families on child planning, prevention and correction of possible health disorders in newborns, in particular, on the problem of nursing premature babies.

Keywords: social work technologies; young family; newborn; health; family planning; charity

Несмотря на то, что частота осложненных родов и, в частности, преждевременных в Российской Федерации относительно стабильна и составляет 5-10\% от числа родившихся детей, однако увеличивается и удельный вес «глубоко» и «экстремально» недоношенных детей. Данное явление можно объяснить возрастанием влияния пренатальных факторов риска, которые связаны с падением социального и нравственного уровня населения, неполноценным питанием, вредными пристрастиями (не только самих женщин, но и их окружения), а также социально обусловленными инфекциями, стрессовыми и экологическими нагрузками, и, как следствие, неудовлетворительным состоянием здоровья беременных женщин, патологическим течением беременности и родов (Хохлачева, 2006; Бурцев, 2017). 
Рождение ребенка раньше срока является полной неожиданностью для родителей, которые оказываются совершенно не готовыми к проблеме ни практически, ни информационно, ни психологически. Родители попадают в информационный вакуум, что порой усугубляет и без того непростую ситуацию.

Одну из первостепенных ролей наряду с качественной и своевременной медицинской помощью играет и подход самих родителей к уходу за ранним малышом, в том числе их грамотность и эмоциональная устойчивость.

Благотворительным фондом «Право на чудо» был создан как проект для оказания информационной поддержки, жизненно необходимой семьям, столкнувшимся с рождением недоношенного ребенка, его выхаживанием и поддержанием здоровья, а также родным и близким этих людей.

В рамках проекта родители недоношенных детей получают информацию о состоянии их малыша и формируют практические навыки, необходимые для успешного выхаживания их ребенка в стационаре и после выписки из него.

Благотворительный фонд «Право на чудо» был образован в апреле 2015 г. Его миссией является содействие сохранению качества жизни детей, родившихся раньше срока, и их семей. При создании фонда была поставлена цель - объединить усилия общества, бизнеса и государства в решении проблем преждевременных родов и недоношенности и значительно снизить риск тяжелых осложнений и смертности. В деятельности фонда заложены основные принципы:

- Помогать детям, родившимся раньше срока, реализовывать их право на жизнь, семью, здоровье и полноценный образ жизни;

- Работать вместе с лучшими врачами и помогать им в их работе;

- Доносить информацию в доступной форме;

- Быть прозрачными в своей деятельности;

- Взаимодействовать со всеми, кто может повлиять на процесс выхаживания детей — от семьи до органов государственной власти;

- Взаимодействовать с семьями детей, родившихся раньше срока, и воспринимать их как часть команды фонда, разделяющую одни и те же цели и принципы;

- Собирать благотворительные пожертвования и расходовать их строго в соответствии с уставными целями ${ }^{1}$.

В ноябре 2015 г. благотворительный фонд «Право на чудо» был принят в Европейскую Ассоциацию организаций помощи недоношенным детям (The European Foundation for the Care of Newborn Infants, EFCNI).

${ }^{1}$ https://pravonachudo.ru/o-fonde/zadachi-fonda/ 
Научные труды Московского гуманитарного университета 2019 № 5

Перед сотрудниками фонда стоят многообразные задачи: «обеспечить доступ к информации о реальных рисках преждевременных родов и путях их снижения; способствовать снижению травматичности родовспоможения и применению технологий, помогающих сохранить здоровье недоношенного ребенка и снизить риск последующих осложнений. А также оказывать психологическую поддержку семьям и, в первую очередь, матерям, переживающим стресс из-за преждевременных родов и переживаний за состояние здоровья ребенка; осуществлять профилактику отказов от детей, родившихся раньше срока; противодействовать «выгоранию» сотрудников, работающих в родильных домах и перинатальных центрах; помочь близким ребенка, родившегося раньше срока получить максимально полную и достоверную информацию о его состоянии здоровья; о том, какая помощь ему необходима и где ее можно получить; способствовать реализации комплексного динамического, своевременного и многопрофильного подхода к выхаживанию и реабилитации детей, родившихся раньше срока; защищать права пациентов, подопечных фонда» ${ }^{1}$.

Для реализации поставленных задач в фонде «Право на чудо» были созданы специальные программы, среди которых стоит выделить горячую линию поддержки семей с недоношенными детьми; школу для родителей; проект по обеспечению специальным оборудованием остронуждающихся недоношенных детей с тяжелой формой бронхо-легочной дисплазии, нуждающимся в кислородной терапии и контроле сатурации кислорода на дому.

Одна из программ фонда — «Чудо дети» - направлена на разработку эффективных механизмов информирования общественности о проблемах недоношенных новорожденных и их семей. Важно доносить достоверную информацию о недоношенности населению, чтобы повышать уровень знаний общества и менять предвзятое отношение к недоношенным детям. В данном вопросе помогает создание и развитие интернет-ресурса благотворительного фонда «Право на чудо», а так же групп в различных социальных сетях и организация волонтерских групп при перинатальных и реабилитационных центрах.

Сайт фонда (https://pravonachudo.ru) позволяет не только донести информацию обществу о недоношенных детях, а первостепенно помогает родителям самих деток и их родственникам узнать все о преждевременных родах, о недоношенных детях, о своих правах, а также как пережить утрату. Для этого на сайте фонда в разделе «Семья» создана страница «База знаний». Также здесь можно найти литературу по данным темам.

Главной целью фонда «Право на чудо» является объединение усилий общества, бизнеса и государства в решении проблем преждевременных ро-

${ }^{1}$ https://pravonachudo.ru/o-fonde/zadachi-fonda/ 
дов и недоношенности и значительно снизить риск тяжелых осложнений и смертности.

Перед сотрудниками фонда стоят задачи: обеспечить доступ к информации о реальных рисках преждевременных родов и путях их снижения; способствовать снижению травматичности родовспоможения и применению технологий, помогающих сохранить здоровье недоношенного ребенка и снизить риск последующих осложнений. Фонд призван оказывать психологическую поддержку семьям и, в первую очередь, матерям, переживающим стресс из-за преждевременных родов и переживаний за состояние здоровья ребенка; осуществлять профилактику отказов от детей, родившихся раньше срока; а также противодействовать «выгоранию» сотрудников, работающих в родильных домах и перинатальных центрах; помочь близким ребенка, родившегося раньше срока получить максимально полную и достоверную информацию о его состоянии здоровья; помощь ему необходима и где ее получить; способствовать реализации комплексного динамического, своевременного и многопрофильного подхода к выхаживанию и реабилитации детей, родившихся раньше срока; защищать права пациентов, подопечных фонда.

Для реализации поставленных задач в фонде «Право на чудо» были созданы специальные программы: «Горячая линия», «Школа для родителей недоношенных детей», «Поддержка кислородным оборудованием», «Благотворительное рукоделие», «Чудо дети».

Рождение ребенка раньше срока является полной неожиданностью для родителей, которые оказываются совершенно не готовыми к проблеме - ни практически, ни информационно, ни психологически. Родители попадают в информационный вакуум, что порой усугубляет и без того непростую ситуацию.

Одну из первостепенных ролей наряду с качественной и своевременной медицинской помощью играет и подход самих родителей к уходу за ранним малышом, в том числе их грамотность и эмоциональная устойчивость.

Сложившаяся ситуация повлияла на идею создания в благотворительном фонде «Право на чудо» проекта «Школа для родителей недоношенных детей», чтобы комплексно охватить наиболее чувствительные аспекты жизни семей с недоношенными детьми, дать не разовую поддержку, а комплексное сопровождение с возможностью оказания психологической и юридической помощи. Для реализации проекта сотрудниками фонда были поставлены следующие цели:

- повышение качества помощи семьям с детьми, рожденными раньше срока;

- содействие укреплению уверенности родителей в собственных мо- 
Научные труды Московского гуманитарного университета 2019 № 5

ральных и физических силах при выхаживании и реабилитации недоношенного ребенка.

Определены задачи проекта «Школа для родителей недоношенных детей»:

- предоставление родителям достоверной информации и знаний, необходимых для успешного выхаживания недоношенного ребенка и ежедневного ухода за ним после выписки из стационара;

- ознакомление родителей с анатомо-физиологическими особенностями преждевременно рожденных детей, осложнениями, возникающими у детей, рожденных раньше срока, их причинами и профилактикой;

- формирование у родителей навыков ежедневного ухода за младенцем, вскармливания (включая грудное вскармливание) и оказания неотложной помощи ребенку в экстренных ситуациях, которые могут возникнуть после выписки недоношенного ребенка из стационара.

Участниками Школы являются родители, чьи недоношенные дети находятся в отделениях реанимации и интенсивной терапии новорожденных, а также в отделениях патологии новорожденных и недоношенных детей медицинских организаций. Для родителей становится необходимым повышение уровня знаний по уходу за недоношенным ребенком после выписки из стационара и оказания ему неотложной помощи в экстренных ситуациях; появления уверенности в своих знаниях и навыках, необходимых для успешного выхаживания малыша и последующего ухода за ним; снижения уровня стресса в связи с преждевременными родами; а также повышения у родителей уровня доверия к врачам, медицинским сестрам, когда родители начинают слушать и слышать рекомендации, у них пропадает агрессия и улучшается взаимодействие с медперсоналом.

Групповые консультационные занятия для родителей недоношенных детей, находящихся в стационаре, проводятся четыре раза в месяц врачами-специалистами лечебно-профилактических учреждений с закреплением необходимых базовых навыков ежедневного ухода за младенцем, вскармливания и оказания неотложной помощи ребенку в экстренных ситуациях по темам. Программа занятий разработана на основе выявленных потребностей пациентов, столкнувшихся с проблемой недоношенности, и включает четыре модуля по наиболее востребованным темам:

1. Уход за кожей недоношенного ребенка;

2. Вскармливание (включая грудное вскармливание);

3. Бронхолегочная дисплазия;

4. Ретинопатия и неотложная помощь в экстренных ситуациях.

В рамках первой темы участники консультации знакомятся с анатомо-физиологическими особенностями преждевременно рожденных детей, 
температурным режимом недоношенных детей, основами гигиены младенца, требованиям к одежде для недоношенных детей. На консультации уделено внимание формированию навыков ухода за кожей недоношенного малыша после выписки из стационара, включая умывание, подмывание, применение подгузников, купание, уход за пуповинным остатком и пупочной ранкой.

При изучении темы «Вскармливание (включая грудное вскармливание)» родителей знакомят с анатомо-физиологическими особенностями пищеварительной системы недоношенных новорожденных, трудностями, возникающими при кормлении недоношенных детей, способами и видами вскармливания детей, рожденных раньше срока, необходимостью обеспечения своевременного введения прикорма и дополнительных продуктов питания. А также с преимуществами грудного вскармливания, как для ребенка, так и для матери, узнают о ценностях материнского молока, особенно для преждевременно рожденных детей. На консультации особое внимание уделяют формированию у мам навыков вскармливания преждевременно рожденных детей, включая грудное вскармливание.

Во время занятий по бронхолегочной дисплазии участники консультации изучают анатомо-физиологические особенности дыхательных путей у недоношенных детей, течение бронхолегочной дисплазии (БЛД) как хронического заболевания у недоношенных детей, профилактику БЛД, осложнения, их причинами и профилактикой. Во время занятий формируются навыки помощи недоношенному ребенку с БЛД после выписки из стационара.

Особое внимание в Школе уделяют теме «Ретинопатия и неотложная помощь в экстренных ситуациях». Врачи затрагивают проблему ретинопатии у недоношенного ребенка, причинами, периодами развития и стадиями ретинопатии, ее диагностикой и лечением. Основное время занятия отводится формированию навыков поведения родителей в экстренных ситуациях, которые могут возникнуть после выписки недоношенного ребенка из стационара (гипертермия, апное (временная остановка дыхания), судороги, колики).

В рамках проекта «Школа для родителей недоношенных детей» также проходят психологические групповые консультации для родителей недоношенных детей по вопросам выхаживания, раннего развития ребенка и профилактики инвалидности. Занятия проводит перинатальный семейный психолог с обширным опытом работы с родителями недоношенных детей.

Важным направлением проекта является проведение удаленного сопровождения семей с недоношенными детьми в течение 2-х месяцев (60 дней), имеющими риск осложнений после выписки из стационара. При реализации данного направления проводится регулярное удаленное психологическое сопровождение, что позволяет содействовать социальной адапта- 
ции всех членов семьи недоношенного ребенка, что напрямую влияет на повышение качества жизни малыша.

Стоит отметить, что проект помогает не только родителям, оказавшимся в сложной жизненной ситуации, но и медицинскому персоналу, который подвержен синдрому эмоционального истощения и выгорания. Специфика работы медицинских специалистов, связанная с дефицитом рабочего времени, плотным графиком и летальными исходами, не позволяет врачам выстраивать конструктивное общение с родителями пациентов. Родители критически воспринимают советы и рекомендации медицинского персонала. В адрес фонда поступали письма с потребность в дополнительной информационной и психологической поддержке врачей.

С целью профилактики профессионального выгорания и налаживанию контакта с пациентами, находящимися в состоянии стресса проект «Школа для родителей недоношенных детей» стала предоставлять психологическую помощь медицинским специалистам.

В 2015 г. была открыта первая Школа родителей недоношенных детей в Московском областном перинатальном центре. На сегодняшний день проект вырос до 33 школ в 22 регионах Российской Федерации. Лидирует по количеству Москва - в столице работает четыре школы для родителей недоношенных детей.

Проведенный нами в 2018 г. социологический опрос учащихся Школы выявил, что большинство родителей $(96,75 \%)$ отметили получение пользы, удовлетворения от консультаций, новых знаний и компетенций. Дальше с небольшим отставанием $(96 \%$ и $95,375 \%)$ у родителей стоят повышение уверенности в своих силах в воспитании и реабилитации недоношенного ребенка и эмоциональной устойчивости. Чуть более $1 / 3$ родителей $(34,075 \%)$ отметили повышение уровня осведомленности по вопросам ухода, оказания первой помощи, профилактике заболеваний недоношенных детей.

Благотворительный фонд «Право на чудо» планирует развивать данный проект, для чего был разработан алгоритм запуска Школы для родителей недоношенных детей на базе лечебно-профилактического учреждения (ЛПУ). Для открытия Школы необходимо:

- Составить соглашение между фондом и ЛПУ о сотрудничестве и проведении совместных мероприятий;

- Определить консультантов по каждой теме (с учетом взаимозаменяемости);

- Определить место, день недели и время, удобное для проведения занятий (продолжительность 1-го занятия - примерно 1 час), составить график проведения занятий; 
- Фонд предоставляет материалы в помощь для подготовки планов-конспектов и презентаций по каждой теме, а также анкеты для участниц с целью проверки уровня усвоения материала, дистанционно консультирует по организационным вопросам;

- Фонд предоставляет информационно-справочные буклеты по каждой теме для раздачи участницам в конце каждого занятия.

В 2016 г. благотворительный фонд помощи недоношенным детям «Право на чудо» запустил первую и единственную на данный момент в России бесплатную горячую линию поддержки семей с недоношенными детьми. Звонки принимают квалифицированные психологи, прошедшие специальную подготовку и хорошо осведомленные о проблемах, волнующих семьи, а также врач-неонатолог. По мере необходимости подключаются другие профильные специалисты для консультаций.

Прием звонков открыт бесплатно и круглосуточно по номеру 8 (800) 5552924, консультации также ведутся через онлайн чат на сайте Фонда: http://pravonachudo.ru.

Горячая линия занимает важную нишу в оказании немедицинского сервиса, который жизненно необходим семьям, столкнувшимся с проблемой преждевременных родов и недоношенных детей, а также родным и близким этих людей. Это социально значимая услуга, предоставляемая гражданам для получения квалифицированных информационного характера консультаций, экстренной психологической помощи или оперативного решения вопросов, связанных с лечением и реабилитацией преждевременно рожденных детей.

Проекты «Горячая линия» и «Школа для родителей недоношенных детей» созданы для оказания информационной поддержки, жизненно необходимой семьям, столкнувшимся с рождением недоношенного ребенка, а также родным и близким этих людей.

Консультационные занятия для родителей недоношенных детей с закреплением необходимых базовых навыков ежедневного ухода за младенцем, вскармливания и оказания неотложной помощи ребенку в экстренных ситуациях по темам: «Уход за кожей недоношенного ребенка», «Вскармливание (включая грудное вскармливание)», «Бронхолегочная дисплазия», «Ретинопатия» и «Неотложная помощь в экстренных ситуациях» проводятся консультантами из числа врачей-специалистов лечебно-профилактических учреждений.

Психологические групповые консультации проходят для родителей недоношенных детей по вопросам выхаживания, раннего развития ребенка и профилактики инвалидизации. Занятия проводит перинатальный семей- 
ный психолог с обширным опытом работы с родителями недоношенных детей.

В рамках проектов «Горячая линия» и «Школа для родителей недоношенных детей» предоставляется психологическая помощь родителям детей, рожденных раньше срока, а также медицинским специалистам с целью профилактики профессионального выгорания и налаживанию контакта с пациентами, находящимися в состоянии стресса.

Предоставление консультационной юридической поддержки в проекте «Горячая линия» помогает решить вопросы с ранней медицинской реабилитацией ребенка, получение бесплатной медицинской помощи, помощь в подготовке документов для оформления инвалидности и ряда других сложностей, связанные с правовыми вопросами.

На «Горячей линии» помогают решить две важнейшие социальные проблемы после рождения недоношенного ребенка - это сохранение целостности семьи и преодоление страха перед следующей беременностью.

Уход за недоношенным ребенком не очень прост, и особенно труден если недоношенный ребенок оказывается инвалидом. Для успешных результатов в уходе необходимо владеть определенными навыками: соблюдение распорядка дня, кормления, гигиены новорожденного, освоения реабилитационных методик. Но зачастую у отцов нет на это не времени, не психологического настроя. Многим известно, что большинство мужчин гордятся своим продолжением рода. Появление на свет «слабого» ребенка демонстрирует его неполноценность, несостоятельность. Внимание матери полностью переключается на ребенка, в связи с этим возникает некоторая конкуренция между «особенным» ребенком и отцом. Окончательным результатом такой конкуренции может быть уход отца из семьи.

В данной ситуации благотворительный фонд «Право на чудо» предлагает удаленное психологическое сопровождение семьи по «Горячей линии». Специалисты линии помогают налаживанию взаимоотношений между отцом и матерью, между отцом и ребенком.

Современные технологии позволяют выходить детей с экстремально низкой массой тела. Из выживших недоношенных детей большая часть становятся полноценными членами общества. Успех в выхаживании недоношенных детей с очень низкой массой тела при рождении находится в непосредственной зависимости от уровня профессионализма медицинского персонала (как врачей, так и среднего медицинского состава), адекватности реанимации и интенсивной терапии, от оснащения медицинских учреждений необходимой аппаратурой, медикаментами, вспомогательными средствами. 
Проект «Школа для родителей недоношенного ребенка» вызвал большой интерес у представителей медицинского сообщества после представления его на профессиональных медицинских мероприятиях. И если первоначально идея создания «Школ для родителей недоношенных детей» появилась, исходя из запросов и потребностей в информационно-психологической поддержке самих родителей, то сейчас все больше заявок об организации подобных школ на базе своих учреждений при поддержке фонда поступает от врачей и медицинских организаций.

Консультанты Горячей линии поддержки семей с недоношенными детьми благотворительного фонда «Право на чудо» обеспечивают психолого-социальную, информационную, юридическую поддержку, при необходимости направляли к профильным специалистам.

Еженедельно (или с той частотой, которую определили при первом контакте для контроля состояния членов семьи, осуществляющим уход, и самого ребенка) они связываются по оставленному контактному телефону.

На основе анализа медико-социальной работы благотворительного фонда «Право на чудо» предлагаются следующие практические рекомендации для формирования у членов семьи с недоношенным ребенком навыков содействия в реализации индивидуальной программы реабилитации для восстановления, поддержания и улучшения здоровья ребенка:

- для формирования оптимального взаимодействия в диаде «мать дитя», необходимо повышать уровень абилитационной компетентности родителей посредством их обучения и активизации родительской позиции;

— пройти курс занятий в «Школе для родителей недоношенных детей» для получения практических навыков вскармливания недоношенных детей, ухода за кожей недоношенных новорожденных детей после выписки из стационара, оказания первой помощи при бронхолегочной дисплазии, оказания неотложной помощи в экстренных ситуациях;

- в случаях появления вопросов обращаться в службу круглосуточной поддержки «Горячая линия» фонда «Право на чудо» за своевременной профессиональной помощью в решении социальной, психологической и юридической проблемы, возникшей в семье с недоношенным ребенком;

- посещать психологические групповые консультации по решению вопросов в выхаживании, особенностях раннего развития ребенка и профилактики инвалидизации; диатра;

- с пониманием относиться к рекомендациям врача-неонатолога и пе-

- выстраивать здоровые отношения в семье;

- принимать роль родителя; 


\section{— понимать чувства ребенка;}

Безусловно, нельзя исключать важность профилактических медико-социальных мероприятий, направленных на сокращение количества развития патологий у женщин детородного возраста. Крайне важно еще до беременности задуматься над тем, как избежать преждевременных родов. И здесь необходима профилактика и своевременная подготовка. Прежде всего, перед зачатием следует провести обследование организма, а при выявлении каких-либо нарушений, пройти полный курс лечения.

Прежде всего, к профилактике преждевременных родов относится устранение возможных причин (чаще всего, инфекций) еще на этапе планирования беременности:

- Обратиться к гинекологу в женскую консультацию на самых ранних стадиях беременности, для постановки на учет и наблюдения, особенно, если в анамнезе имеются преждевременные роды, аборты или самопроизвольные выкидыши. Регулярные посещения врача создают гораздо больше возможностей для будущей мамы проходить медицинский осмотр, консультироваться по вопросам диеты и быть осведомленной обо всем процессе, что она должна пройти;

- Увеличить период между беременностями;

- Беременная женщина должна следить за своим питанием, употреблять богатую витаминами и минералами пищу или специальные витаминные комплексы для беременных. Низкие концентрации витаминов, минералов, белков и энергии в организме влекут за собой риск уменьшения кровообращения и повышенной материнской инфекции, которые оба могут потенциально увеличить риск преждевременных родов.

В целях профилактических мероприятий необходимо строго выполнять следующие рекомендации:

- Соблюдение режима отдыха и питья. Адекватный режим отдыха и достаточное количество жидкости способствуют хорошей циркуляции крови, кислорода, витаминов и питательных веществ для растущего плода;

- Необходимо исключить эмоциональные потрясения, умственное и социальное напряжение. Депрессия, семейные неприятности и стрессовые обстоятельства, такие, как тяжелые материальные трудности, также были связаны с началом преждевременных родов;

- Своевременная сдача анализов, выявление и лечение инфекций во время беременности;

- Профилактика, выявление и лечение возникших во время беременности осложнений;

— Регулярный УЗИ-контроль за развитием плода; 
- Если имеется риск преждевременных родов, то во время критических сроков (2-3, 4-12 и 18-22 недели) рекомендуется обязательная госпитализация в роддом. В стационаре проводится профилактическая терапия, направленная на сохранение беременности;

- Знать симптомы преждевременных родов. Они включают: сокращение матки, схваткообразные боли в низу живота, боли в спине, и выделения из влагалища;

- Важно помнить, что преждевременные роды начинаются неожиданно, чаще всего рядом не оказывается медицинских работников, способных сразу же оказать необходимую помощь. Таким образом, самый лучший способ уберечься от преждевременных родов - соблюдать вышеперечисленные рекомендации;

- Когда будущая мать здорова, а беременность протекает без патологий, то маловероятно, что у нее начнутся преждевременные роды.

\section{СПИСОК ЛИТЕРАТУРЫ}

Бурцев, С. П. (2017) Безопасность жизнедеятельности: курс лекций. М.: Изд-во Московского гуманитарного университета.

Хохлачева, Т. В. (2006) Недоношенный ребёнок. Сестринский процесс при уходе за недоношенным ребенком: учебно-методическое пособие. Энгельс.

Дата поступления: 15.09.2019 г.

Бурцев Сергей Петрович - кандидат медицинских наук, профессор кафедры социологии Московского гуманитарного университета. Адрес: 111395, Россия, г. Москва, ул. Юности, д.5. Тел.: +7 (499) 374-6021. E-mail: sergei-burcew@mail ru.

Жуков Александр Валерьевич - сотрудник благотворительного фонда «Право на чудо». Адрес: 107023, Россия, г. Москва, ул. Суворовская, д. 12, кв. 9. Тел.: +7 (499) 374-60-21. E-mail: zhukovav1@yandex ru

Burtsev Sergey Petrovich, Candidate of Medicine, Professor, Department of Sociology, Moscow University for the Humanities. Postal address: 5, Yunosti St., Moscow, Russian Federation, 111395. Tel.: +7 (499) 374-6021. E-mail: sergeiburcew@mail.ru

Zhukov Aleksandr Valeryevich, Employee, Charity Fund "Right to a Miracle". Postal address: Apt. 9, 12, Suvorovskaya St., Moscow, Russian Federation, 107023. E-mail: zhukovav1@yandex.ru 


\section{Для цитирования:}

Бурцев С. П., Жуков А. В. Медико-социальная работа с молодыми семьями по проблеме планирования семьи [Электронный ресурс] // Научные труды Московского гуманитарного университета. 2019. № 5. URL: http://journals.mosgu.ru/trudy/article/view/1051(дата обращения: дд.мм.гг.). DOI: 10.17805/trudy.2019.5.2 